\title{
Non-steady State Chloride Migration and Binding in Cracked Self-compacting Concrete
}

\author{
MA Baoguo', MU Song ${ }^{1,2 *}$, De Schutter Geert ${ }^{2}$ \\ (1.School of Materials Science and Engineering, Wuhan University of Technology, Wuhan 430070, China; 2.Magnel Laboratory for Concrete \\ Research, Department of Structural Engineering, Ghent University, Ghent 9052, Belgium)
}

\begin{abstract}
We adopted a notch method to study the influence of crack width (macro level) on chloride transport and binding of cracked concrete under a non-steady state migration test. The results show that migration coefficient of cracked concrete increases with increasing crack width up to a critical value $(0.43 \mathrm{~mm})$, for the whole concrete or the area close to crack; the increase of migration coefficient could be independent from crack parameter when a critical crack width is reached. For chloride binding, Langmuir isotherms of cracked concrete samples exhibit the similar decreasing trend as crack width increases from 0.27 to $1.96 \mathrm{~mm}$. The increased current value could be responsible for the trend based on the hypothesis of electric force.
\end{abstract}

Key words: crack; chloride diffusion; migration test; chloride binding; crack width

\section{Introduction}

In recent years, transport properties and servicelife prediction of cracked concrete have already been concerned by lots of researchers. In order to simulate the real crack, both non-destructive notch and destructive mechanic methods are developed to investigate the influence of crack on transport properties $^{[1-11]}$. As far as chloride transport is concern, migration test accelerated by electric force is an effective and rapid method to determine chloride resistance of concrete. B Gérard et al ${ }^{[1]}$ proposed a mathematical model to predict the effect of cracking on the concrete diffusivity based on the crack assumption of uniform size and even distribution. Djerbi et al ${ }^{[2]}$ adopted a splitting tensile test to study the effects of traversing cracks of concrete on chloride transport at a steady state migration test. Jang et $a l^{[3]}$ found that

(c)Wuhan University of Technology and SpringerVerlag Berlin Heidelberg 2013 (Received: Oct. 26, 2012; Accepted: May 9, 2013)

MABaoguo(马保国): Prof:; E-mail: mbgjob@163.com.

*Corresponding author: MU Song(穆松): Ph D; E-mail: musonglemontree@126.com

Funded by China Scholarship Council, the Special Research Fund (BOF) of Ghent University, and National Natural Science Foundation of China (No.51178363) the steady state migration coefficients increase with increasing crack widths when reaching $135 \mu \mathrm{m}$ of the threshold crack width. Park et $a l^{[4]}$ also found transient chloride migration coefficient in cracked concrete increases rapidly with increasing crack width from 0.1 to $0.4 \mathrm{~mm}$, and obtained its relationship with crack width. Marsavina et $a l^{[5]}$ and Audenaert et $a l^{[6]}$ adopted a notch method to study the influence of cracks on chloride penetration depth by means of non-steady state migration tests.

However, the reported researches just measured the crack width on the surface of concrete, but do not quantify all crack parameters, such as crack length, depth, connectivity and density etc. One thing is worthy of notice, the splitting test is easy to produce several cracks on the concrete surface when operating the test. Besides, most of the crack reported is micro or meso level of crack, the value of which is lower than $0.2 \mathrm{~mm}$. The other thing could not be neglected is the research on chloride binding of cracked concrete.

Based on the problem, NT BUILD 492 (nonsteady state migration test), a good theoretical foundation, short duration and simple calculation, were adopted to study the influence of artificial crack width on chloride transport and binding of cracked concrete. Considering the increasing application of self-compacting concrete (SCC) in huge construction 
projects, it is interesting to choose SCC as the studied subject.

\section{Experimental}

\subsection{Concrete composition}

One SCC mix (M1) was used for the tests: 360 $\mathrm{kg} / \mathrm{m}^{3}$ CEM I $52.5 \mathrm{~N}, 240 \mathrm{~kg} / \mathrm{m}^{3}$ calcite filler (Carmeuse MS), $853 \mathrm{~kg} / \mathrm{m}^{3}$ river sand $0 / 4,698 \mathrm{~kg} / \mathrm{m}^{3}$ river gravel $2 / 8$ and $165 \mathrm{~kg} / \mathrm{m}^{3}$ of water. According to literature ${ }^{[7]}$, the following fresh properties have been obtained: 785 mm of slump flow, $10.8 \mathrm{~s}$ of V-funnel time, $82 \%$ of L-box, $3.43 \%$ of sieve stability, $3.2 \%$ of air content and $2375 \mathrm{~kg} \cdot \mathrm{m}^{-3}$ of density. The concrete specimens were stored in a climate room at $20 \pm 2{ }^{\circ} \mathrm{C}$ and more than 90 $\%$ R.H. until the age of 60 days. At 28 days, the M1 has a compressive strength of $74.6 \mathrm{MPa}$.

\subsection{Testing methods}

\subsubsection{Crack preparation and characterization}

A notch method was used to prepare cracks by means of the positioning and removal after approximately 4 hours of thin copper sheets inside the specimen ${ }^{[5,6,8]}$. A copper sheet with a length of $60 \mathrm{~mm}$ but a different width from 0.1 to $2 \mathrm{~mm}$ were placed up to a depth of $20 \mathrm{~mm}$ in the concrete. After migration test, image analysis was conducted on the cut surface of the concrete sample to measure crack width and depth. The average crack width was determined based on measuring 30 points with a uniform distribution along the crack.

\subsubsection{Migration test}

A non-steady state migration test (CTH)-NT BUILD 492 1999-was carried out on the obtained concrete specimens. Prior to the migration test, the specimens were vacuum saturated with a saturated $\mathrm{Ca}(\mathrm{OH})_{2}$ solution. Then an external electrical potential of 30 volts was applied on the specimens for 24 hours that forced the chloride ions from the $10 \% \mathrm{NaCl}$ solution to migrate into the specimens (the exposed face is casting surface with crack).

For each group of concrete, chloride profiles including water soluble chloride and acid soluble chloride were determined on three concrete specimens, which were the same specimens as used for the crack characterization. The mean value of three specimens was calculated.

2.2.3 Water soluble chloride

After migration test and crack characterization, all concrete specimens were ground into powder layer by layer (Approximately $2 \mathrm{~mm}$ thickness per layer). $2.5 \mathrm{~g}$ dried powder (with size less than $160 \mu \mathrm{m}$ ) and 50 $\mathrm{mL}$ de-ionised water were used to prepare a solution. Storing the solution for 24 hours at $20{ }^{\circ} \mathrm{C}, 5 \mathrm{~mL}$ solution is titrated to determine the chloride content.

\subsubsection{Acid soluble chloride}

Using $5 \mathrm{~mL}$ of $0.3 \mathrm{~mol} / \mathrm{L}$ nitric acid, $40 \mathrm{~mL}$ de-ionised water and the powder mentioned above, a solution was prepared to determine the chloride content. After boiling the solution, it was filtered into $100 \mathrm{~mL}$ flask with deionised water. At last, $10 \mathrm{~mL}$ of the filtered solution was pipetted for determination of the concentration of chloride. The mass percentage unit of concentration for water soluble chloride can be transformed into molar concentration unit, $\mathrm{mol} / \mathrm{L}$ :

$$
C^{\prime}=\frac{1000 \times C}{35.45 \times \omega}
$$

where $C^{\prime}$ is the water soluble chloride content, $\mathrm{mol} / \mathrm{L}$; $\omega$ is the water content of concrete by mass of sample, which is equal to $4.12 \%$ in the present research.

\section{Results}

\section{I Crack evaluation}

The results of crack width and depth are shown in Table 1. For the notation, M1 means SCC without a crack; W means the crack width, $\mathrm{mm}$; the number behind $\mathrm{W}$ stands for the width of copper sheet to prepare the crack; E means chloride transport by electric field. From Table 1, we observe a difference between preset and measured values in crack width or depth. However, the variation coefficients of

Table 1 Results of different crack parameters

\begin{tabular}{|c|c|c|c|c|c|c|c|}
\hline Sample & Mean width/mm & $S D^{\mathrm{a}} / \mathrm{mm}$ & $V C^{\mathrm{b}} / \%$ & Mean depth/mm & $S D / \mathrm{mm}$ & $V C / \%$ & Length $/ \mathrm{mm}$ \\
\hline M1EW0.1 & 0.27 & 0.09 & 33.33 & 17.05 & 0.88 & 5.17 & 60.0 \\
\hline M1EW0.2 & 0.44 & 0.06 & 14.77 & 18.50 & 0.91 & 4.91 & 60.0 \\
\hline M1EW0.5 & 0.86 & 0.22 & 25.86 & 20.16 & 0.31 & 1.52 & 60.0 \\
\hline M1EW 1 & 1.25 & 0.05 & 5.70 & 20.27 & 0.84 & 4.13 & 60.0 \\
\hline M1EW2 & 1.96 & 0.24 & 12.07 & 18.95 & 0.06 & 0.34 & 60.0 \\
\hline
\end{tabular}

Note: ${ }^{a} S D$ is the standard deviation; ${ }^{\mathrm{b}} V C$ is the variation coefficient 
crack width or depth are acceptable for all concrete specimens. The measured values of crack length are in good agreement with the designed value $(60 \mathrm{~mm})$.

\subsection{Chloride concentration}

The contents of water and acid soluble chloride are shown in Fig. 1 and 2 separately. For the water soluble chloride, all chloride profiles decreased with increasing distance from the exposure surface. The cracked concrete samples have higher chloride contents than sound concrete (M1E) when the distance is above $10 \mathrm{~mm}$. However, different cracked concrete samples seem to have no significant discrepancy. For the acid soluble chloride, similar results to water soluble chloride are observed in Fig.2. Besides, the content of acid soluble chloride is higher than that of water soluble chloride.

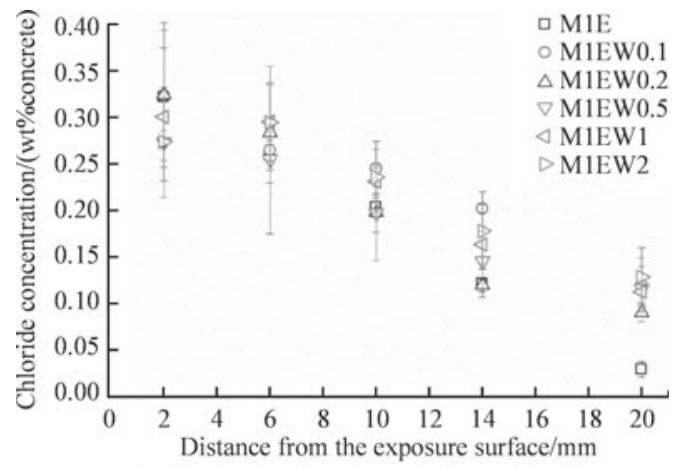

Fig. 1 Content of water soluble chloride

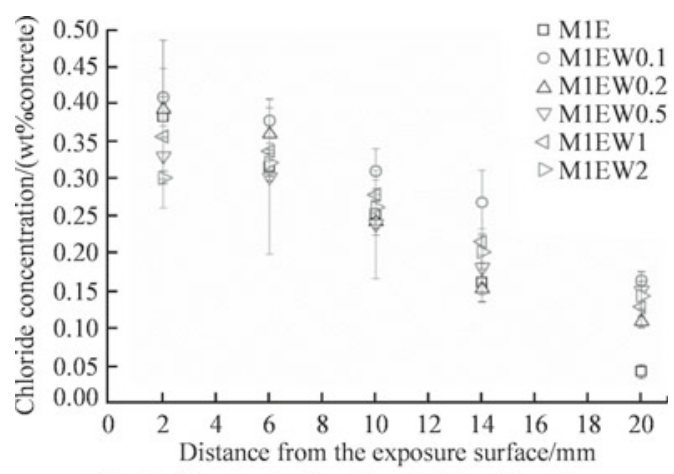

Fig.2 Content of acid soluble chloride

The error bars (equal to standard deviation) have some higher fluctuations at the distance ranging from 2 to $6 \mathrm{~mm}$. On the one hand, this phenomenon could be explained by the thickness fluctuation of a grinding layer; on the other hand, the cracked concrete could include different quantities of chloride salts in cracks, which resulted in significant fluctuation.

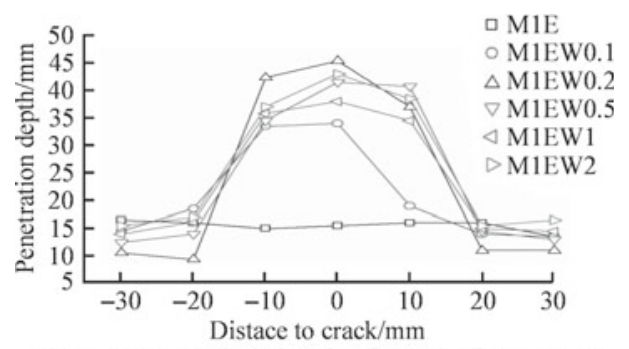

Fig.3 Penetration depth of cracked concrete with different crack widths

\subsection{Penetration depth}

After migration test, $0.1 \mathrm{~mol} / \mathrm{L}$ silver nitrate was sprayed on the split concrete specimens to measure chloride penetration depth in cracked concrete. Fig. 3 shows the penetration profiles in different cracked concrete samples. The horizontal axis of the figure means the distance to the crack in which $0 \mathrm{~mm}$ stands for the position of crack (The same below). From Fig.3, higher values of penetration depth are observed at the distance to crack ranging from -10 to $10 \mathrm{~mm}$, when comparing with sound concrete (M1E). Besides, the penetration depth increases with increasing crack width in that range, except for M1EW0.2 and M1EW0.5. The unexpected order in the results for M1EW0.2 and M1EW0.5 could be caused by random error during the measurements.

All average values of penetration depth are summarized in Table 2. Firstly, the average penetration depth increases slightly with increasing crack width in the entire range from -30 to $30 \mathrm{~mm}$. Secondly, the values of penetration depth show a bilinear behavior when the distance to the crack is rising from -10 to $10 \mathrm{~mm}$, while the M1EW1 sample has an unexpected fluctuation. Thirdly, the penetration depth seems to make a little change when the distance to crack is increasing from -30 to $-20 \mathrm{~mm}$ or from 20 to $30 \mathrm{~mm}$. The results of average penetration depth demonstrate that chloride transport in cracked concrete is inclined to choose the part close to the crack as the shortcut to ingress into concrete.

Table 2 Average penetration depth of concrete with different crack width/mm

\begin{tabular}{ccccccc}
\hline Distance to crack & M1E & M1EW0.1 & M1EW0.2 & M1EW0.5 & M1EW1 & M1EW2 \\
\hline From-30 to $30 \mathrm{~mm}$ & 15.50 & 21.00 & 23.82 & 24.39 & 24.00 & 26.14 \\
From-10 to $10 \mathrm{~mm}$ & 15.50 & 28.83 & 41.58 & 38.92 & 36.10 & 39.50 \\
From-30 to $-20 \mathrm{~mm}$ & 16.25 & 16.50 & 10.00 & 13.25 & 15.10 & 16.25 \\
From 20 to $30 \mathrm{~mm}$ & 14.75 & 13.75 & 11.00 & 13.75 & 14.75 & 16.00 \\
\hline
\end{tabular}




\subsection{Migration coefficient}

From the penetration profile, the non-steady state $D_{\text {nssm }}$ chloride migration coefficient can be calculated in the following equation described in NT BUILD 492 $1999^{[9]}$ :

$$
\begin{aligned}
D_{\mathrm{nssm}}= & \frac{0.0239 \cdot(273+T) \cdot L}{(U-2) \cdot t} \\
& \left(x_{d}-0.0238 \sqrt{\frac{(273+T) \cdot L \cdot x_{d}}{U-2}}\right)
\end{aligned}
$$

where, $D_{\text {nssm }}$ is the non-steady-state migration coefficient, $\times 10^{-12} \mathrm{~m}^{2} / \mathrm{s} ; U$ is the absolute value of the applied voltage, $\mathrm{V} ; T$ is the average value of the initial and final temperatures in the anolyte solution, ${ }^{\circ} \mathrm{C} ; L$ is the thickness of the specimen, $\mathrm{mm} ; x_{\mathrm{d}}$ is the average value of the penetration depths, $\mathrm{mm} ; t$ is the test duration, hour.

According to Eq.(2), non-steady state migration coefficients of different cracked concrete samples can be calculated into Table 3 . The results of migration coefficient show similar trend as for the results of the penetration depth. When increasing the crack width from 0 to $1.96 \mathrm{~mm}$, the migration coefficient increases slightly from $6.95 \times 10^{-12}$ to $12.09 \times 10^{-12} \mathrm{~m}^{2} / \mathrm{s}$ as the distance to the crack ranging from -30 to $30 \mathrm{~mm}$. By comparison, the migration coefficient increases from $6.95 \times 10^{-12}$ to $18.67 \times 10^{-12} \mathrm{~m}^{2} / \mathrm{s}$ as the distance ranging from -10 to $10 \mathrm{~mm}$. Therefore, the migration coefficient of concrete nearby the crack is significantly higher than that of the whole cracked concrete. Besides, the migration coefficients of concrete nearby the crack also exhibit a bilinear behavior.

\subsection{Chloride binding}

The previous results show the influence of crack width on chloride transport at transient migration condition. The present part investigates the influence of crack width on chloride binding of cracked concrete under the role of an electric field. On basis of the relationship between bound chloride and free chloride, the following binding isotherm is proposed to describe the relation ${ }^{[10]}$ :

Langmuir binding:

$$
C_{b}=\alpha C_{f} /\left(1+\beta C_{f}\right)
$$

where, $C_{b}$ is the content of bound chloride, $C_{f}$ is the free chloride content, and $\alpha$ and $\beta$ are binding parameters.

All Langmuir binding isotherms are presented in Fig.4. For the cracked concrete, the results show that the content of bound chloride decreased with increasing crack width when content of water soluble chloride is higher than $1.08 \mathrm{~mol} / \mathrm{L}$. As the content is below this value, the content of bound chloride is close together for M1EW0.2, M1EW0.5 and M1EW1. The sound concrete (M1E) nearly has a content of bound chloride in the middle of M1EW0.1 and M1EW0.2. Theoretically, M1E should have the highest content of bound chloride in all the binding isotherms. However, the surface chloride concentration of cracked concrete

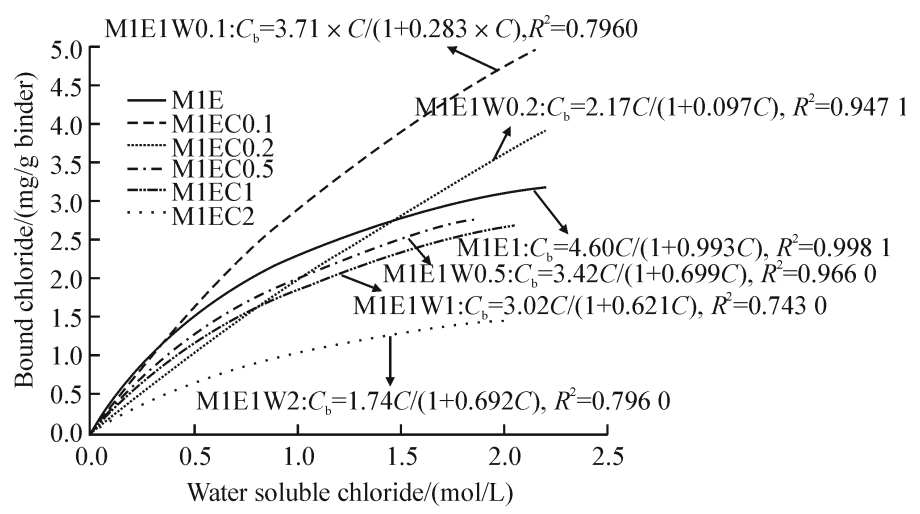

Fig. 4 Langmuir binding isotherms of cracked concrete

Table 3 Migration coefficient of concrete with different crack widths $/\left(10^{-12} \mathrm{~m}^{2} / \mathrm{s}\right)$

\begin{tabular}{ccccccc}
\hline Distance to crack & M1E & M1EW0.1 & M1EW0.2 & M1EW0.5 & M1EW1 & M1EW2 \\
\hline From-30 to $30 \mathrm{~mm}$ & 6.95 & 9.66 & 11.09 & 11.47 & 11.16 & 12.09 \\
From-10 to $10 \mathrm{~mm}$ & 6.95 & 13.53 & 19.96 & 18.77 & 17.18 & 18.67 \\
From-30 to-20 mm & 7.31 & 7.46 & 4.34 & 5.95 & 6.79 & 7.28 \\
From 20 to $30 \mathrm{~mm}$ & 6.58 & 6.13 & 4.82 & 6.20 & 6.62 & 7.16 \\
\hline
\end{tabular}


could be different from that of sound concrete.

\section{Discussion}

\section{I Influence of crack width on chloride transport}

The average penetration depth increases slightly with increasing crack width, in the whole testing range from -30 to $30 \mathrm{~mm}$. However, the distance to the crack has a significant influence on the penetration depth of cracked concrete. In general, the maximum penetration depth is found around $10 \mathrm{~mm}$ of the distance to the crack. The non-steady state migration coefficients of cracked concrete samples show similar results as the penetration depth: When the distance to crack increases from -10 to $10 \mathrm{~mm}$, the migration coefficients of cracked concrete samples with different crack parameters show one order of magnitude higher values than that of sound concrete. Besides, we observed a bilinear relationship between the crack parameters and the migration coefficient in Fig.5.

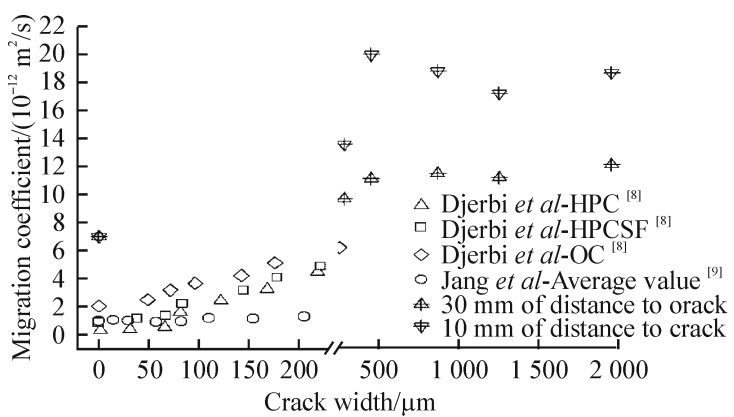

Fig. 5 The relationship between migration coefficients and crack widths

The results of migration coefficients are in good agreement with previous researches. Gérard and Marchand's results ${ }^{[1]}$ show that steady state migration coefficients of concrete with different crack widths are one order of magnitude higher than sound concrete. Djerbi et $a l^{[2]}$ observed that the steady state migration coefficient increases with increasing crack width for ordinary and high performance concrete (Fig.5). Jang et $a l^{[3]}$ also found that the steady state migration coefficients increase with increasing crack widths when reaching $135 \mu \mathrm{m}$ of the threshold crack width (Fig.5).

The bilinear behavior has already been reported by the following researchers. Audenaer ${ }^{[6]}$ observes that an increasing maximum penetration depth is obtained for crack widths between 0 and $0.1 \mathrm{~mm}$. For crack widths between 0.1 and $0.2 \mathrm{~mm}$, this increase seems to be independent from the crack width. Djerbi ${ }^{[2]}$ also obtains a bilinear relation between the crack width at the concrete surface and the diffusion coefficient

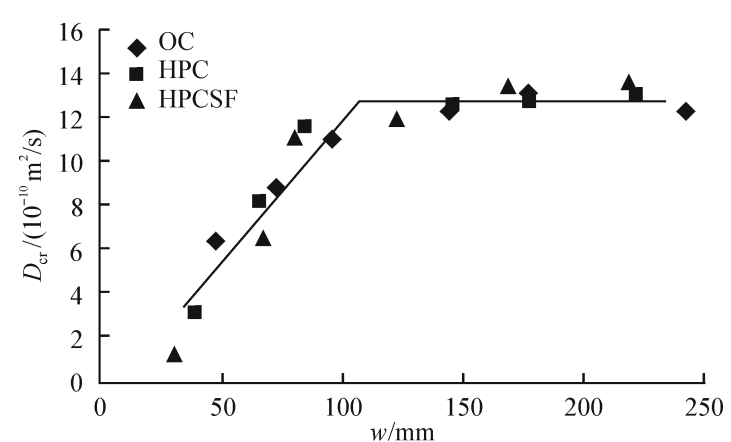

Fig.6 Effect of crack width on diffusivity through the crack from Djerbi et al

through the crack in a steady state migration test (Fig.6).

Based on the discussion as mentioned above, we conclude that the influence of crack width on migration coefficient of cracked concrete could be divided into two parts: for the whole concrete or the area close to crack, the migration coefficient of cracked concrete increases with increasing crack parameter up to a critical value; the increase of migration coefficient could be independent from crack parameter when a critical crack width is reached. The critical value of crack width is $0.43 \mathrm{~mm}$ for the ranges studied.

\subsection{Influence of crack width on chloride binding}

According to literature ${ }^{[8]}$, a theoretical equation is proposed to describe the relationship between electric force and current value based on some assumptions.

$$
F=\frac{I \cdot t \cdot U}{d}
$$

where, $F$ is electric force, $U$ is voltage, $d$ is distance between cathode and anode, $I$ is current, and $t$ is time.

In the present research, $t, U$ and $\mathrm{d}$ are constant, so $F$ is dependent on current $I$. Therefore, a higher current value leads to a higher electric force. Theoretically, the higher electric force has some negative effect on binding capacity of cement matrix, and maybe it is the reason why migration test has the lower bound chloride content than diffusion test in Castellotea et $a l^{[11]}$.

In addition to electric force, the chloride binding also depends on concentration of chloride ions. Although the total chloride content of the migration test is constant, the surface content of chloride could be different for different testing samples.

The current values of testing samples are presented in Table 4. The average value of current increases with increasing crack width, which means the electric force is increased too. The increasing electric force results in decreased bound chloride, which is consistent with our experimental results. However, some cracked concrete samples have a higher chloride 
Table 4 Current values before (initial) and after (ultimate) non-steady state migration

\begin{tabular}{ccccccc}
\hline Current $/ \mathrm{mA}$ & M1E & M1EW0.1 & M1EW0.2 & M1EW0.5 & M1EW1 & M1EW2 \\
\hline Initial current & 43 & 50 & 47 & 43 & 57 & 57 \\
Ultimate current & 43 & 57 & 47 & 60 & 57 & 57 \\
Average value & 43 & 53.5 & 47 & 51.5 & 57 & 57 \\
\hline
\end{tabular}

binding than sound concrete sample (M1E). The reason could be that sound concrete sample (M1E) has a low surface concentration of chloride than cracked concrete samples. Yuan ${ }^{[10]}$ mentioned that a higher concentration of external chloride resulted in a high level of chloride binding. The further validation is necessary in future.

\section{Conclusions}

a) The present paper studied the influence of crack width on chloride transport and binding of cracked concrete at a non-steady state migration test. After the test, the results show that cracked concrete samples have higher chloride content and penetration depth than sound concrete. However, the influence of crack width on chloride content at different depths of concrete seems not significant for the concrete samples with increasing crack width from 0.27 to $1.96 \mathrm{~mm}$;

b) The migration coefficient of cracked concrete increases with increasing crack parameter up to a critical value for the whole concrete or the area close to crack; the increase of migration coefficient could be independent from crack parameter when a critical crack width is reached. The critical value of crack width is $0.43 \mathrm{~mm}$ for the ranges studied.

c) The Langmuir binding isotherms of cracked concrete samples exhibit a similar decreasing trend as crack width increases from 0.27 to $1.96 \mathrm{~mm}$. The increased current value could be responsible for the trend based on the hypothesis of electric force.

\section{References}

[1] B Gérard and J Marchand. Influence of Cracking on the Diffusion Properties of Cement Based Materials - Part I: Influence of Continuous
Cracks on the Steady-state Regime[J]. Cem. Concr. Res., 2000, 30 (1) $37-43$

[2] A Djerbi, S Bonnet, A Khelidj, et al. Influence of Traversing Crack on Chloride Diffusion into Concrete[J]. Cem. Concr. Res., 2008, 38(6): $877-883$

[3] S Y Jang, B S Kimand, B H Oh. Effect of Crack Width on Chloride Diffusion Coefficients of Concrete by Steady-state Migration Tests[J] Cem. Concr. Res., 2011, 41 (1): 9-19

[4] S S Park, S J Kwon, S H Jung. Analysis Technique for Chloride Penetration in Cracked Concrete Using Equivalent Diffusion and Permeation[J]. Constr. Build. Mater., 2012 , 29: 183-192

[5] L Marsavina, K Audenaert, G De Schutter, et al. Experimental and Numerical Determination of the Chloride Penetration in Cracked Concrete[J]. Constr. Build. Mater., 2009, 23 (1): 264-274

[6] K Audenaert, G De Schutter and L Marsavina. Influence of Cracks and Crack Width on Penetration Depth of Chlorides in Concrete[J]. Eur. J. Environ. Civ. Eng., 2009, 13 (5): 561-572

[7] G De Schutter, P J M Bartos, P Domone, et al. Self-Compacting Concrete[M]. Caithness: Whittles Publishing, 2008

[8] S Mu, G De Schutter and B G Ma. Study on Chloride Binding of Selfcompacting Concrete with Different Crack Lengths[C]. Proceeding of the International Conference on Advances in Construction Materials through Science and Engineering, Hong Kong, 2011

[9] NT Build 492. Concrete, Mortar and Cement-Based Repair Materials: Chloride Migration Coefficient from Non-steady-state Migration Experiments (S).NORDTEST, 1999

[10] Q Yuan, C J Shi, and G De Schutter, et al. Chloride Binding of Cementbased Materials Subjected to External Chloride Environment: A Review[J]. Constr. Build. Mater., 2009,23 (1): 1-13

[11] M Castellote, C Andrade, and C Alonso. Chloride-binding Isotherms in Concrete Submitted to Non-steady-state Migration Experiments[J]. Cem. Concr. Res., 1999, 29(11): 1 799-1 806 